\title{
Saponins and Sapogenins from Brachiaria decumbens Stapf
}

\author{
Viviane S. Pires ${ }^{a}$, Alexandre T. C. Taketa ${ }^{b}$, Grace Gosmann $^{a}$ and Eloir P. Schenkel $^{* a}$ \\ ${ }^{a}$ Faculdade de Farmácia, Universidade Federal do Rio Grande do Sul (UFRGS), Av. Ipiranga, 2752, 90610-000 \\ Porto Alegre, RS - Brazil \\ ${ }^{b}$ Kekulé-Institut für Organische Chemie und Biochemie der Rheinischen Friedrich-Wilhelms-Universität, \\ Bonn, Germany
}

\begin{abstract}
Quatro saponinas esteroidais e três sapogeninas foram identificadas das partes aéreas de Brachiaria decumbens. As estruturas desses compostos foram estabelecidas através de métodos químicos e espectroscópicos (RMN de ${ }^{1} \mathrm{H}$ e ${ }^{13} \mathrm{C}$, HMBC, HMQC) como $3 \beta$-metóxi-lanost-9(11)-eno (1), diosgenina (2a), iamogenina (2b), 3-O- $\beta$-D-glicopiranosil-24(S)-etil-22E-deidrocolesterol (3a), 3O- $\beta$-D-glicopiranosil-24(R)-etil-22E-deidrocolesterol (3b), dioscina $(4 \mathbf{a})$ e $3-\mathrm{O}-\{\alpha$-Lramnopiranosil-( $1 \rightarrow 4)$-[ $\alpha$-L-ramnopiranosil-( $1 \rightarrow 2)]-\beta$-D-glicopiranosil $\}$-25(S)-espirost-5-en-3 $\beta$-ol (4b). Esses compostos foram isolados pela primeira vez em $B$. decumbens, sendo que o composto 4b não foi ainda descrito na natureza conforme revisão realizada.
\end{abstract}

Four steroidal saponins and three sapogenins were identified from aerial parts of Brachiaria decumbens. Their structures were established by chemical and spectroscopic means $\left({ }^{1} \mathrm{H}\right.$ and ${ }^{13} \mathrm{C}$ NMR, HMBC, HMQC) as 3 $\beta$-methoxy-lanost-9(11)-ene (1), diosgenin (2a), yamogenin (2b), 3 O- $\beta$-D-glucopyranosyl-24(S)-ethyl-22E-dihydrocholesterol (3a), 3-O- $\beta$-D-glucopyranosyl-24(R)ethyl-22E-dihydrocholesterol (3b), dioscin (4a) and 3-O- $\{\alpha$-L-rhamnopyranosyl- $(1 \rightarrow 4)-[\alpha-\mathrm{L}-$ rhamnopyranosyl-( $(1 \rightarrow 2)]-\beta$-D-glucopyranosyl $\}-25(S)$-spirost-5-en-3 $\beta$-ol (4b). All these compounds were isolated for the first time from $B$. decumbens and compound $\mathbf{4 b}$ is described for the first time as far as we know.

Keywords: Brachiaria decumbens, steroidal saponins, dioscin, diosgenin, yamogenin, triterpene.

\section{Introduction}

Brachiaria decumbens Stapf belongs to a group of plants capable of inducing hepatogenous photosensitizations $^{1-4}$ similar to those described for Panicum spp., ${ }^{5-8}$ Tribulus terrestris, ${ }^{8,9}$ Agave lecheguilla ${ }^{10}$ and Narthecium ossifragum $^{8}$. These species are all known to contain steroidal saponins which have been associated with deposition of crystalloid material within the biliary system and photosensitization. In our previous paper, ${ }^{11}$ we reported the isolation and structural determination of steroidal sapogenins present in rumen contents of lambs intoxicated with $B$. decumbens. In this paper we describe the structural elucidation of triterpene and steroidal compounds isolated from the aerial parts of $B$. decumbens as free aglycones or as saponins. The latter compounds were isolated as epimeric pairs.

\footnotetext{
* e-mail: schenkel@ccs.ufsc.br
}

\section{Experimental}

\section{Plant material and extraction}

Aerial parts from B. decumbens Stapf were collected in Teutônia, State of Rio Grande do Sul, Brazil, in January 2000. A herbarium specimen is on deposit in the Herbarium of the Botany Department of the Federal University of Rio Grande do Sul (Herbarium ICN, Porto Alegre, Brazil, voucher $\mathrm{n}^{\circ}$ 121456). Air-dried powdered plant material (500 g) was extracted during 7 days at room temperature with ethanol. The solvent was evaporated and the residual alcoholic phase was suspended in water. This suspension was partitioned with dichloromethane and the main dichloromethane compounds were isolated using column chromatography.

\section{Isolation}

Part of the dichloromethane extract (5 g) was chromatographed on a silica gel column and eluted with dichloro- 
methane:ethanol $(99: 1 ; 90: 10 ; 80: 20$ and 70:30, v/v). Fractions were pooled according to thin-layer chromatography (TLC) analysis. Fractions $2-10(250 \mathrm{mg})$ containing compound $\mathbf{1}$ as main component, were further purified by silica gel column chromatography, eluting with hexane and resulting in pure compound $\mathbf{1}(12.5 \mathrm{mg})$. Fractions $30-40$ (500 mg), 50-60 (350 mg) and 68-81 (500 mg) containing compounds $\mathbf{2}, \mathbf{3}$ and $\mathbf{4}$ as main components were submitted to successive silica gel column chromatography, eluting with hexane:ethyl acetate $(3: 1, \mathrm{v} / \mathrm{v})$, dichlorometane:ethanol (9:1, v/v) and dichlorometane: ethanol (7:3, v/v), respectively. By these procedures compounds 2 (33 $\mathrm{mg}), 3$ (15 mg) and 4 (40 mg) were obtained.

\section{General procedures}

Dichloromethane extract and fractions were chromatographed on a silica gel column (Merck, particle size: 230-400 mesh) at atmospheric pressure. TLC was carried out on silica gel (Merck, $\mathrm{GF}_{254}$ ) using hexane:ethyl acetate $(3: 1, \mathrm{v} / \mathrm{v})$ and dichlorometane:ethanol $(7: 3, \mathrm{v} / \mathrm{v})$. Compounds were visualized by heating $\left(120^{\circ} \mathrm{C}\right)$ using the anisaldehyde-sulfuric acid-spray. FAB-MS spectrum was performed on a MS50 spectrometer. ${ }^{1} \mathrm{H}$ NMR and ${ }^{13} \mathrm{C}$ NMR spectra were recorded on Bruker AMX 500 spectrometer.

$3 \beta$-methoxy-lanost-9(11)-ene (1). ${ }^{1} \mathrm{H} \mathrm{NMR}(500 \mathrm{MHz}$, $\left.\mathrm{CDCl}_{3}\right): \delta 1.83(\mathrm{H}-1), 1.91,1.75(\mathrm{H}-2), 2.70(\mathrm{H}-3), 0.89(\mathrm{H}-$ 5), 1.67, 1.72 (H-6), 1.37 (H-7), 2.19 (H-8), 5.25 (H-11), 1.93, 2.09 (H-12), 1.28 (H-15), 1.65, 1.71 (H-16), $1.62(\mathrm{H}-$ 17), 0.67 (H-18), 0.91 (H-19), 1.41 (H-20), 0.77 (H-21), 1.38 (H-22), 1.38 (H-23), 1.16 (H-24), 1.54 (H-25), 0.89 (H-26), 0.90 (H-27), 1.06 (H-28), 1.00 (H-29), 0.83 (H-30), $3.40\left(\mathrm{OCH}_{3}\right) \cdot{ }^{13} \mathrm{C} \mathrm{NMR}\left(125 \mathrm{MHz}, \mathrm{CDCl}_{3}\right) \delta 36.4(\mathrm{C}-1)$, 22.9 (C-2), 89.0 (C-3), 39.4 (C-4), 53.4 (C-5), 21.6 (C-6), 34.3 (C-7), 42.2 (C-8), 149.0 (C-9), 37.5 (C-10), 115.2 (C11), 37.5 (C-12), 44.5 (C-13), 47.4 (C-14), 30.1(C-15), 28.5 (C-16), 51.4 (C-17), 14.8 (C-18), 18.8 (C-19), 36.6 (C-20), 18.9 (C-21), 36.9 (C-22), 24.5 (C-23), 39.9 (C-24), 28.4 (C-25), 22.9 (C-26), 23.2 (C-27), 22.6 (C-28), 28.6 (C-29), $16.8(\mathrm{C}-30), 57.9\left(\mathrm{OCH}_{3}\right)$.

Compound $2 a$. diosgenin. ${ }^{1} \mathrm{H}$ NMR and ${ }^{13} \mathrm{C}$ NMR data $\left(\mathrm{CDCl}_{3}\right)$ : same as in references 15 and 17 .

Compound $2 \boldsymbol{b}$. yamogenin. ${ }^{1} \mathrm{H}$ NMR and ${ }^{13} \mathrm{C}$ NMR data $\left(\mathrm{CDCl}_{3}\right)$ : same as in references 15 and 17 .

3-O- $\beta$-D-glucopyranosyl-24(S)-ethyl-22E-dihydrocholesterol (3a). ${ }^{1} \mathrm{H} \mathrm{NMR}$ data $\left(500 \mathrm{MHz}, \mathrm{C}_{5} \mathrm{D}_{5} \mathrm{~N}\right): \delta 1.71$, 0.98 (H-1), 2.12, 1.74 (H-2), 3.94 (H-3), 2.72, 2.46 (H-4), 5.34 (H-6), 1.88, 1.54 (H-7), 1.36 (H-8), 0.89 (H-9), 1.45, 1.45 (H-11), 1.97, 1.09 (H-12), $0.92(\mathrm{H}-14), 1.02,1.53(\mathrm{H}-$ 15), 1.26, 1.84 (H-16), 1.08 (H-17), 0.88 (H-18), 0.95 (H19), 2.03 (H-20), 0.90 (H-21), 5.20 (H-22), 5.06 (H-23),
1.56 (H-24), 1.54 (H-25), 1.07 (H-26), 0.85 (H-27), 0.95 (H-28), 0.87 (H-29), 5.05 (glc H-1), 4.05 (glc H-2), 4.28 (glc H-3), 4.28 (glc H-4), 3.97 (glc H-5), 4.41, 4.56 (glc H6); ${ }^{13} \mathrm{C} \mathrm{NMR}\left(125 \mathrm{MHz}, \mathrm{C}_{5} \mathrm{D}_{5} \mathrm{~N}\right): \delta 37.6(\mathrm{C}-1), 30.4(\mathrm{C}-2)$, 78.2 (C-3), 39.5 (C-4), 141.1 (C-5), 122.1 (C-6), 32.3 (C7), 32.2 (C-8), 50.5 (C-9), 37.1 (C-10), 21.5 (C-11), 40.0 (C-12), 42.5 (C-13), 57.0 (C-14), 24.7 (C-15), 28.7 (C-16), 56.2 (C-17), 12.3 (C-18), 19.2 (C-19), 41.0 (C-20), 19.6 (C-21), 139.0 (C-22), 129.6 (C-23), 51.6 (C-24), 32.4 (C25), 21.7 (C-26), 19.4 (C-27), 25.9 (C-28), 12.7 (C-29), 102.7 (glc C-1), 75.5 (glc C-2), 78.8 (glc C-3), 71.8 (glc C4), 78.7 (glc C-5), 63.0 (glc C-6).

3-O- $\beta$-D-glucopyranosyl-24(R)-ethyl-22E-dihydrocholesterol (3b). ${ }^{1} \mathrm{H} \mathrm{NMR}\left(500 \mathrm{MHz}, \mathrm{C}_{5} \mathrm{D}_{5} \mathrm{~N}\right): \delta 1.71,0.98$ (H-1), 2.12, 1.74 (H-2), 3.94 (H-3), 2.72, 2.46 (H-4), 5.34 (H-6), 1.88, 1.54 (H-7), 1.36 (H-8), 0.89 (H-9), 1.45, 1.45 (H-11), 1.97, 1.09 (H-12), 0.92 (H-14), 1.02, 1.53 (H-15), $1.26,1.84$ (H-16), 1.08 (H-17), 0.88 (H-18), 0.95 (H-19), 2.03 (H-20), 0.87 (H-21), 5.20 (H-22), 5.06 (H-23), 1.56 (H-24), 1.54 (H-25), 0.85 (H-26), 0.92 (H-27), 1.28 (H-28), 0.66 (H-29), 5.05 (glc H-1), 4.05 (glc H-2), 4.28 (glc H-3), 4.28 (glc H-4), 3.97 (glc H-5), 4.41, 4.56 (glc H-6). ${ }^{13} \mathrm{C} \mathrm{NMR}$ $\left(125 \mathrm{MHz}, \mathrm{C}_{5} \mathrm{D}_{5} \mathrm{~N}\right): \delta 37.6(\mathrm{C}-1), 30.4(\mathrm{C}-2), 78.2(\mathrm{C}-3)$, 39.5 (C-4), 141.1 (C-5), 122.1 (C-6), 32.3 (C-7), 32.2 (C8), 50.5 (C-9), 37.1 (C-10), 21.5 (C-11), 40.1 (C-12), 42.6 (C-13), 57.1 (C-14), 24.7 (C-15), 28.7 (C-16), 56.4 (C-17), 12.3 (C-18), 19.2 (C-19), 41.0 (C-20), 20.2 (C-21), 139.0 (C-22), 129.6 (C-23), 51.6 (C-24), 32.4 (C-25), 19.4 (C26), 21.5 (C-27), 23.6 (C-28), 12.2 (C-29), 102.7 (glc C-1), 75.5 (glc C-2), 78.8 (glc C-3), 71.8 (glc C-4), 78.7 (glc C5), 63.0 (glc C-6).

Compound 4. FAB-MS (positive mode) $\mathrm{m} / \mathrm{z} 907.6$ $[\mathrm{M}+\mathrm{K}]^{+}, 891.6[\mathrm{M}+\mathrm{Na}]^{+}, 869.5[\mathrm{M}+\mathrm{H}]^{+}, 723.3[(\mathrm{M}+\mathrm{H})-$ $146]^{+}, 415.3[(\mathrm{M}+\mathrm{H})-146-146-162]^{+}, 413.3$ [aglycone-H] ${ }^{+}$, 395.3 [aglycone- $\left.\mathrm{H}_{3} \mathrm{O}\right]^{+}$.

Compound 4a. ${ }^{1} \mathrm{H}$ NMR and ${ }^{13} \mathrm{C}$ NMR data $\left(\mathrm{C}_{5} \mathrm{D}_{5} \mathrm{~N}\right)$ : same as in references 17 and 22.

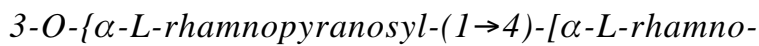
pyranosyl- $(1 \rightarrow 2)]-\beta$-D-glucopyranosyl\}-25(S)-spirost-5en-3 $\beta$-ol (4b). ${ }^{1} \mathrm{H}$ NMR (500 MHz, $\left.\mathrm{C}_{5} \mathrm{D}_{5} \mathrm{~N}\right): \delta 1.72,0.97$ (H-1), 2.06, 1.84 (H-2), 3.86 (H-3), 2.75, 2.75 (H-4), 5.30 (H-6), 1.84, 1.45 (H-7), 1.55 (H-8), 0.89 (H-9), 1.42, 1.42 (H-11), 1.66, 1.07 (H-12), 1.03 (H-14), 2.01, 2.01 (H-15), 4.48 (H-16), 1.77 (H-17), 1.06 (H-18), 1.05 (H-19), 1.87 (H-20), 1.13 (H-21), 1.44, 1.87 (H-23), 2.13, 1.34 (H-24), 1.80 (H-25), 4.03, 3.34 (H-26), 1.12 (H-27), 4.95 (glc H-1), 4.22 (glc H-2), 4.18 (glc H-3), 4.39 (glc H-4), 3.62 (glc H5), 4.08, 4.21 (glc H-6), 6.39 (rha H-1), 4.84 (rha H-2), 4.67 (rha H-3), 4.37 (rha H-4), 4.95 (rha H-5), 1.75 (rha H-6), 5.85 (rhaI H-1), 4.62 (rhaI H-2), 4.53 (rhaI H-3), 4.33 (rhaI H-4), 4.93 (rhaI H-5), 1.62 (rhaI H-6). 
${ }^{13} \mathrm{C}$ NMR (125 MHz, $\left.\mathrm{C}_{5} \mathrm{D}_{5} \mathrm{~N}\right): \delta 37.6(\mathrm{C}-1), 30.3(\mathrm{C}-2)$, 78.1 (C-3), 39.1 (C-4), 140.9 (C-5), 121.9 (C-6), 32.4 (C-7), 31.8 (C-8), 50.4 (C-9), 37.2 (C-10), 21.2 (C-11), 39.9 (C-12), 40.5 (C-13), 56.7 (C-14), 32.3 (C-15), 81.2 (C-16), 63.0 (C17), 16.4 (C-18), 19.5 (C-19), 42.5 (C-20), 15.0 (C-21), 109.4 (C-22), 26.5 (C-23), 26.3 (C-24), 27.6 (C-25), 65.2 (C-26), 15.2 (C-27), 100.4 (glc C-1), 77.9 (glc C-2), 78.2 (glc C-3), 78.6 (glc C-4), 77.0 (glc C-5), 61.3 (glc C-6), 102.1 (rha C1), 72.6 (rha C-2), 72.7 (rha C-3), 74.2 (rha C-4), 69.6 (rha C5), 18.8 (rha C-6), 103.0 (rhaI C-1), 72.9 (rhal C-2), 72.8 (rhaI C-3), 74.0 (rhal C-4), 70.5 (rhaI C-5), 18.6 (rhal C-6).

\section{Results}

Solvent partition and chromatographic procedures allowed the isolation of the main compounds 1-4 (Figure 1) from the aerial parts of $B$. decumbens.

Acid hydrolysis of $\mathbf{3}$ yielded only one sugar identified as glucose (glc), and acid hydrolysis of $\mathbf{4}$ yielded two sugars identified as rhamnose (rha) and glucose (glc). In both cases, the sugars were identified by co-TLC using authentic samples.

The ${ }^{13} \mathrm{C}$ NMR spectrum of compound $\mathbf{1}$ displayed 31 signals, whereas the DEPT spectrum revealed 9 methyl, 10 methylene, 7 methine and 5 quartenary carbon atoms. The presence of an insaturation can be observed in the ${ }^{13} \mathrm{C}$ NMR spectrum by the signals at $\delta_{\mathrm{c}} 149.0(\mathrm{Cq})$ and $\delta_{\mathrm{c}} 115.2$ $(\mathrm{CH})$ and, by one-proton absorbance at $\delta_{\mathrm{H}} 5.25(\mathrm{H}-11)$ in the ${ }^{1} \mathrm{H}$ NMR spectrum. These data suggest a $\Delta^{9(11)}$-lanostene skeleton. The ${ }^{1} \mathrm{H}$ NMR spectrum of $\mathbf{1}$ showed the presence of a singlet at $\delta_{\mathrm{H}} 3.40(3 \mathrm{H})$ correlated with the carbon at $\delta_{\mathrm{c}}$ $57.9\left(\mathrm{OCH}_{3}\right)$, demonstrating the presence of a methoxyl group. Long range correlation peaks were detected between the methoxyl signal and C-3 $\left(\delta_{c} 89.0\right)$. The others signals of $\mathbf{1}$ were established by HMBC, HMQC and ${ }^{1} \mathrm{H},{ }^{1} \mathrm{H}$ COSY experiments. Through detailed comparison of these data with those from literature, ${ }^{12-14} \mathbf{1}$ was identified as $3 \beta$ methoxy-lanost-9(11)-ene.

Compound 2 presented the same Rf value of an authentic sample of diosgenin on silica gel plates (TLC).

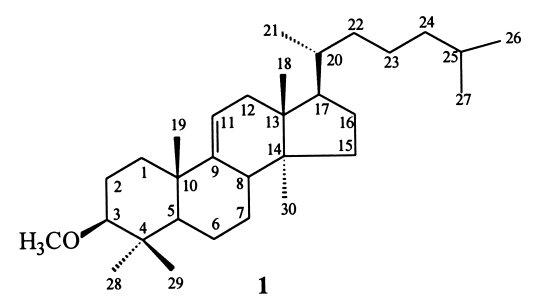

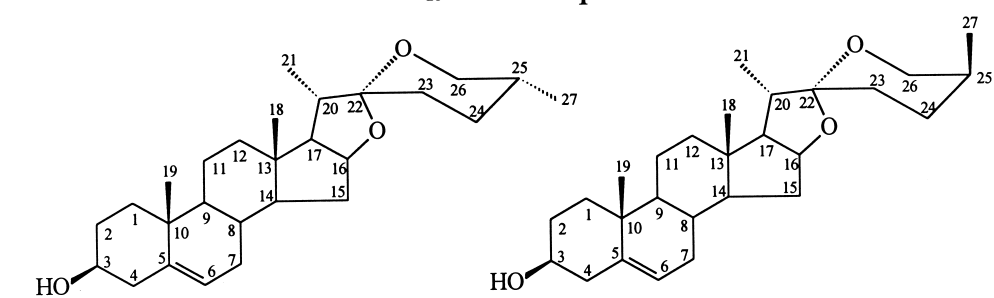

$2 \mathbf{a}$

2b

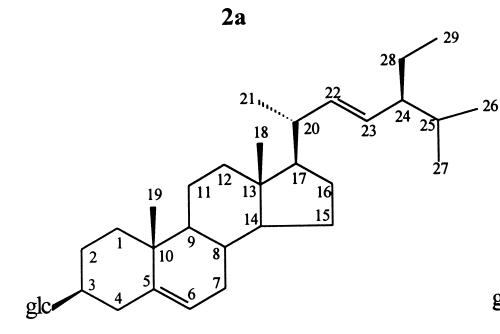

3a

3b

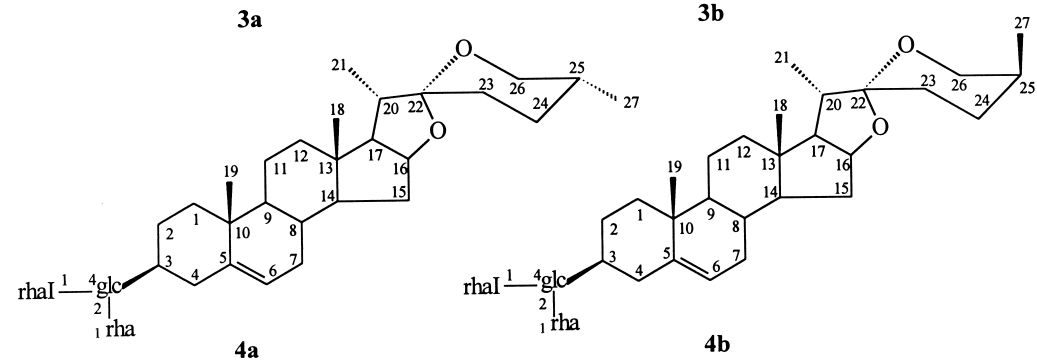

Figure 1. Compounds 1, 2a, 2b, 3a, 3b, 4a, 4b isolated from aerial parts of Brachiaria decumbens 
The IR spectrum showed an hydroxy group $\left(3445 \mathrm{~cm}^{-1}\right)$. The ${ }^{13} \mathrm{C}$ NMR spectrum showed some duplicated signals indicating the presence of an epimeric mixture. All the signals of $\mathbf{2}$ and their connectivity were established by HMBC, HMQC and ${ }^{1} \mathrm{H},{ }^{1} \mathrm{H}$ COSY experiments. It was possible to demonstrate a spiroketal ring system through the presence of carbon quaternary signals at $\delta_{c} 109.7(\mathrm{C}-$ $22, \mathbf{2 a})$ and $110.1(\mathrm{C}-22, \mathbf{2 b}),-\mathrm{OCH}_{2}$ group at $\delta_{\mathrm{c}} 67.2(\mathrm{C}-$ $26,2 \mathrm{a})$ and $65.5(\mathrm{C}-26,2 \mathrm{~b})$, and $\mathrm{OCH}$ group at $\delta_{\mathrm{c}} 81.2(\mathrm{C}-$ $16,2 \mathbf{a})$ and $81.3(\mathbf{C}-16,2 \mathbf{b})$. The epimeric mixture was also characterized through the ${ }^{1} \mathrm{H}$ NMR spectrum by the different multiplicity of the $\mathrm{H}-26$ methylene protons caused by the methyl group at $\mathrm{C}-25$. In this way, compound 2a showed signals at $\delta_{\mathrm{H}} 3.40(t, J 11.0, \mathrm{H}-26 \alpha)$ and at $\delta_{\mathrm{H}}$ 3.49 ( $d d d, J 10.9,4.1,2.1 \mathrm{~Hz}, \mathrm{H}-26 \beta)$, and compound $2 \mathbf{b}$ presented signals at $\delta_{\mathrm{H}} 3.98(d d, J 10.7,2.5 \mathrm{~Hz}, \mathrm{H}-26 \alpha)$ and $\delta_{\mathrm{H}} 3.32(d, J 10.7 \mathrm{~Hz}, \mathrm{H}-26 \beta)$, demonstrating the equatorial and axial protons. Regarding the ${ }^{13} \mathrm{C}$ NMR spectrum, the configuration $25 R$ or $25 S$ can be differentiated by the chemical shifts for C-23, C-24, C-25, C-26 and C-27. Careful comparison of ${ }^{1} \mathrm{H}$ NMR and ${ }^{13} \mathrm{C}$ NMR spectral data of 2 with those of the literature ${ }^{15-18}$ allowed to establish 2 as the 25-epimeric mixture of diosgenin [(25R)-spirost-5en-3 $\beta$-ol] $\mathbf{2 a}$ and yamogenin [(25S)-spirost-5-en-3 $\beta$-ol] $\mathbf{2 b}$.

The ${ }^{13} \mathrm{C}$ NMR of compound 3 displayed 46 signals including, as determined from the DEPT spectrum, 13 methyl, 11 methylene, 18 methine and 4 quaternary carbon atoms, indicating an epimeric mixture through the presence of some duplicated signals. All signals of $\mathbf{3}$ and their connectivity were established by HMBC, HMQC and ${ }^{1} \mathrm{H},{ }^{1} \mathrm{H}$ COSY experiments. The NMR data showed the presence of one sugar identified as glucose $\left(\delta_{\mathrm{H}} 5.05, d, J\right.$ $\left.7.6, \delta_{c} 102.7\right)$ which signals have correlation to $\mathrm{H}-3$. Two insaturations at $\delta_{c} 141.1(\mathrm{Cq}, \mathrm{C}-5)$ and $122.1(\mathrm{CH}, \mathrm{C}-6)$, and $\delta_{c} 139.0(\mathrm{CH}, \mathrm{C}-22)$ and $129.6(\mathrm{CH}, \mathrm{C}-23)$ together with the corresponding olefinic protons at $\delta_{\mathrm{H}} 5.34(\mathrm{H}-6)$, $5.20(\mathrm{H}-22)$ and $5.06(\mathrm{H}-23)$ are characteristic for $\Delta^{5,22}-3 \beta$ hydroxysterols. Comparing to the literature data ${ }^{19,20}$ it was possible to verify that 3 is $24 \alpha$ - and $24 \beta$-stigmastane mixture that can be differentiated by the chemical shifts for C-26 and C-27, which vary about $\delta 2 \mathrm{ppm}$. Therefore, it was concluded that 3 is the epimeric mixture of $3-\mathrm{O}-\beta-\mathrm{D}-$ glucopyranosyl-24(S)-ethyl-22E-dihydrocholesterol (3a) and 3-O- $\beta$-D-glucopyranosyl-24(R)-ethyl-22E-dihydrocholesterol (3b, stigmasterol glucoside).

FAB-MS (positive mode) of compound 4 exhibited ions at $m / z 869.5[\mathrm{M}+\mathrm{H}]^{+}, 891.6[\mathrm{M}+\mathrm{Na}]^{+}$and $907.6[\mathrm{M}+\mathrm{K}]^{+}$ indicating the molecular mass $\mathrm{C}_{45} \mathrm{H}_{72} \mathrm{O}_{16}$. Fragments ions at $\mathrm{m} / \mathrm{z} 723.3$ and $\mathrm{m} / \mathrm{z} 415.3$ indicated the elimination of one methylpentose, and two methylpentoses and one hexose, respectively. ${ }^{21}$ The ${ }^{13} \mathrm{C}$ NMR spectrum displayed 57 signals, determined from the DEPT spectrum as 8 methyl, 15 methylene, 28 methine and 5 quaternary carbon atoms. Careful comparison of ${ }^{13} \mathrm{C}$ NMR spectral data of $\mathbf{4}$ with that of $\mathbf{2}$ showed that $\mathbf{4}$ has same aglycone moieties (an epimeric mixture) and that $\mathbf{4}$ differs structurally from $\mathbf{2}$ only by the presence of sugar signals. This assumption was confirmed by HMBC, HMQC and ${ }^{1} \mathrm{H},{ }^{1} \mathrm{H}-\mathrm{COSY}$ experiments. Comparing the chemical shifts of sugars with the literature data $^{7,17,22}$ it was possible to identify them as two rhamnoses and one glucose. Using the HMBC, HMQC and ${ }^{1} \mathrm{H},{ }^{1} \mathrm{H}-\mathrm{COSY}$ spectra it was possible to identify the interglycosidic linkage. Through all these data we could identify $\mathbf{4}$ as dioscin (4a) and 3-O- $\{\alpha$-L-rhamnopyranosyl- $(1 \rightarrow 4)-[\alpha$-L-rhamnopyranosyl-(1 $\rightarrow 2)]-\beta$-D-glucopyranosyl $\}-25(S)$-spirost-5-en$3 \beta$-ol (4b). The latter compound was not described in the literature, as far as we know.

\section{Discussion}

Over the past years photosensitization in ruminants grazing $B$. decumbens had been associated with sporidesmin from Pithomyces chartarum. However, hepatogenous photosensitization was detected without the presence of $P$. chartarum,,$^{1-4}$ proving the association of the disease with the ingestion of plant saponins as, demonstrated by Miles et al. ${ }^{8}$ Such compounds are metabolized by microbial flora in ruminants to $\beta$-D-glucuronide insoluble salts of episarsasapogenin and epismilagenin.

In the case of $B$. decumbens, the presence of saponins was detected and the aglicone was characterized by GCMS after acid hydrolysis from butanolic extract, ${ }^{2}$ but the chemical structures of these saponins were not elucidated. In the present investigation it was possible to isolate and identify the following compounds: $3 \beta$-methoxy-lanost9(11)-ene (1), diosgenin (2a), yamogenin (2b), 3-O- $\beta$-Dglucopyranosyl-24(S)-ethyl-22E-dihydrocholesterol (3a), 3-O- $\beta$-D-glucopyranosyl-24( $R$ )-ethyl-22E-dihydrocholesterol (3b), dioscin (4a) and, 3-O- $\{\alpha$-L-rhamnopyranosyl- $(1 \rightarrow 4)$ - $[\alpha$-L-rhamnopyranosyl- $(1 \rightarrow 2)]-\beta$-Dglucopyranosyl $\}-25(S)$-spirost-5-en-3 $\beta$-ol (4b). This last compound is the dioscin 25-epimer and, to the best of our knowledge, has not been previously described. All these compounds were isolated for the first time from Brachiaria decumbens. Diosgenin and yamogenin were already isolated from the acid hydrolysis of $B$. decumbens butanolic extract, ${ }^{2}$ but were not isolated in the free form from this plant. These results together with our previous work ${ }^{11,23}$ demonstrated that B. decumbens, as Panicum spp., $T$. terrestris, A. lecheguilla and N. ossifragum, is capable of producing photosensitization in animals due the presence of steroidal saponins and sapogenins. 


\section{Acknowledgements}

We are grateful to Prof. Eberhard Breitmaier from Kekulé-Institut für Organische Chemie der Universität Bonn, Germany for NMR and FAB-MS measurements, to Cláudio Cruz from Department of Veterinary Pathology of the Universidade Federal do Rio Grande do Sul, Brazil for collecting, and Marcos Sobral from the Universidade Federal do Rio Grande do Sul for identifying the plant material. This work was supported by fellowships to V.S. Pires from CAPES (Brazil), and to G. Gosmann and E. P. Schenkel from CNPq (Brazil).

\section{References}

1. Salam Abdullah, A.; Lajis, N.H.; Bremner, J.B.; Davies, N.W., Mustapha, W.; Rajion, M.A.; Vet. Hum. Toxicol. 1992, 34, 154.

2. Smith, B.L.; Miles, C.O.; Vet. Hum. Toxicol. 1993, 35, 256.

3. Meagher, L.P.; Wilkins, A.L.; Miles, C.O.; Collin, R.G.; Fagliari, J.J.; Vet. Hum. Toxicol. 1996, 38, 271.

4. Lemos, R.A.; Salvador, S.C.; Nakazato, L.; Vet. Hum. Toxicol. 1997, 39, 376.

5. Lancaster, M.J.; Vit, I., Lyford, R.L.; Aust. Vet. J. 1991, 68, 281.

6. Bridges, C.H.; Camp, B.J.; Livingstone, C.W.; Bailey, E.M.; Vet. Pathol. 1987, 24, 525.

7. Munday, S.C.; Wilkins, A.L.; Miles, C.O.; Holland, P.T.; J. Agric. Food. Chem. 1993, 41, 267.

8. Miles, C.O.; Wilkins, A.L.; Munday, S.C.; Flaøyen, A.; Holland, P.T.; J. Agric. Food. Chem. 1993, 41, 914.
9. Tapia, M.O.; Giordano, M.A.; Gueper, H.G.; Vet. Hum. Toxicol. 1994, 36, 311.

10. Camp, B.J.; Bridges, C.H.; Hill, D.W.; Patamalal, B.; Wilson, S.; Vet. Hum. Toxicol. 1988, 30, 533.

11. Cruz, C.; Driemeier, D.; Pires, V.S.; Colodel, E.M.; Taketa, A.T.C.; Schenkel, E.P.; Vet. Hum. Toxicol. 2000, 42, 142.

12. Knight, S.A.; Org. Magn. Reson. 1974, 6, 603.

13. Lin, L.; Shiao, M.; Lee, K.R.; J. Nat. Prod. 1989, 52, 595.

14. Ohtsu, H.; Tanaka, R.; Michida, T.; Shingu, T.; Matsunaga, S.; Phytochemistry 1998, 49, 1761.

15. Agrawal, P.K.; Jain, D.C.; Gupta, R.K.; Thakur, R.S.; Phytochemistry 1985, 24, 2479.

16. Agrawal, P.K.; Jain, D.C.; Pathak, A.K.; Magn. Reson. Chem. 1995, 33, 923.

17. Han, X.W.; Yu, H.; Liu, X.M.; Bao, X.; Yu, B.; Li, C.; Hui, Y.Z.; Magn. Reson. Chem. 1999, 37, 140.

18. Puri, R.; Wong, T.C.; Puri, R.K.; Magn. Reson. Chem. 1993, $31,278$.

19. Reginatto, F.H.; Kauffmann, C.; Schripsema, J.; Guillaume, D.; Gosmann, G.; Schenkel, E.P.; J. Braz. Chem. Soc. 2001, 12,32 .

20. Itoh, T.; Kikuchi, Y.; Tamura, T.; Matsumoto, T.; Phytochemistry 1981, 20, 761.

21. Schulten, H.R.; Komori, T.; Kawasaki, T.; Tetrahedron 1977, $33,2595$.

22. Espejo, O.; Llavot, J.C.; Jung, H.; Giral, F.; Phytochemistry 1982, 21, 413.

23. Cruz, C.; Driemeier, D.; Pires, V.S.; Schenkel, E.P.; J. Vet. Diagn. Invest. 2001, 13, 170.

Received: July 25, 2001 Published on the web: December 19, 2001 